\title{
Intestinal permeability in patients with coeliac disease and relatives of patients with coeliac disease
}

\author{
R M van Elburg, J J Uil, C J J Mulder, H S A Heymans
}

Department of

Paediatrics, University

Hospital of Groningen,

Groningen

$\mathrm{R} M$ van Elburg

H S A Heymans

Rijnstate Hospital,

Arnhem, The

Netherlands

J J Uil

Correspondence to:

$\mathrm{R} M$ van Elburg.

Department of

Paediatrics, University

Hospital of Groningen,

PO Box 30001,9700 RB

Groningen, The Netherlands

Accepted for publication

28 July 1992
Department of

Internal Medicine,

C J J Mulder

\begin{abstract}
The functional integrity of the small bowel is impaired in coeliac disease. Intestinal permeability, as measured by the sugar absorption test probably reflects this phenomenon. In the sugar absorption test a solution of lactulose and mannitol was given to the fasting patient and the lactulose/mannitol ratio measured in urine collected over a period of five hours. The sugar absorption test was performed in nine patients with coeliac disease with an abnormal jejunum on histological examination, 10 relatives of patients with coeliac disease with aspecific symptoms but no villous atrophy, six patients with aspecific gastrointestinal symptoms but no villous atrophy, and 22 healthy controls to determine whether functional integrity is different in these groups. The lactulose/mannitol ratio (mean (SEM) is significantly higher in both coeliac disease $(0.243(0.034), p<0.0001))$ and relatives of patients with coeliac disease $(0.158(0.040)$, $\mathrm{p}<0.005)) v$ both healthy controls $(0.043$ $(0.006))$ and patients with aspecific gastrointestinal symptoms $(0.040(0.011))$. The lactulose/mannitol ratio in relatives of coeliac disease patients was significantly lower than in the coeliac disease patient group $(\mathbf{p}=0.04)$. The lactulose/mannitol ratio was the same in healthy controls and patients with aspecific gastrointestinal symptoms. It is concluded that the sugar absorption test is a sensitive test that distinguishes between patients with coeliac disease and healthy controls. The explanation for the increased permeability in relatives of patients with coeliac disease is uncertain. Increased intestinal permeability may be
\end{abstract}

TABLE I Characteristics of patient groups

\begin{tabular}{lllll}
\hline Group & $\begin{array}{l}\text { Healthy } \\
\text { controls } \\
(\mathbf{n}=22)\end{array}$ & $\begin{array}{l}\text { Coeliac } \\
\text { disease } \\
(\mathbf{n}=9)\end{array}$ & $\begin{array}{l}\text { Relatives of } \\
\text { coeliac disease } \\
\text { patients } \\
(\mathbf{n}=10)\end{array}$ & $\begin{array}{l}\text { Aspecific } \\
\text { gastrointestinal } \\
\text { symptoms } \\
(\mathbf{n}=6)\end{array}$ \\
\hline Intestinal biopsy & Not done & $\begin{array}{l}\text { Villous } \\
\text { atrophy }\end{array}$ & $\begin{array}{l}\text { No villous } \\
\text { atrophy } \\
\text { Some }\end{array}$ & $\begin{array}{l}\text { No villous } \\
\text { atrophy } \\
\text { Yes }\end{array}$ \\
$\begin{array}{l}\text { Gastrointestinal } \\
\text { symptoms }\end{array}$ & No & Some & Yes & No \\
$\begin{array}{l}\text { Relatives with coeliac } \\
\text { disease }\end{array}$ & No & Some & & \\
\hline
\end{tabular}

TABLE II Mean (SEM) lactulose, mannitol, and lactulose/mannitol ratio in healthy controls, coeliac disease patients, relatives of coeliac disease patients, and patients with aspecific gastrointestinal symptoms

\begin{tabular}{|c|c|c|c|c|}
\hline Group & $\begin{array}{l}\text { Healthy } \\
\text { controls } \\
(\mathrm{n}=22)\end{array}$ & $\begin{array}{l}\text { Coeliac } \\
\text { disease } \\
\text { patients } \\
(\mathbf{n}=9)\end{array}$ & $\begin{array}{l}\text { Relatives of } \\
\text { coeliac disease } \\
\text { patients } \\
(n=10)\end{array}$ & $\begin{array}{l}\text { Aspecific } \\
\text { gastrointestinal } \\
\text { symptoms } \\
(\mathbf{n}=6)\end{array}$ \\
\hline $\begin{array}{l}\text { Lactulose } \\
\text { Mannitol } \\
\text { I./M ratio }\end{array}$ & $\begin{array}{l}24 \cdot 3(3 \cdot 1) \\
585 \cdot 7(34 \cdot 7) \\
0 \cdot 043(0 \cdot 006)\end{array}$ & $\begin{array}{l}138 \cdot 6+(29 \cdot 1) \\
627 \cdot+(107 \cdot 8) \\
0 \cdot 243+(0 \cdot 034)\end{array}$ & $\begin{array}{l}78 \cdot 5^{\star}(9 \cdot 3) \\
612 \cdot 2(54 \cdot 9) \\
0 \cdot 158^{\star}(0 \cdot 040)\end{array}$ & $\begin{array}{l}25 \cdot 0(6 \cdot 3) \\
63+5(66 \cdot 2) \\
0 \cdot 040(0 \cdot 011)\end{array}$ \\
\hline
\end{tabular}

* $-\mathrm{p}<0.005 ; \dagger=\mathrm{p}<0.0001 v$ healthy controls (Mann Whitney U test). related to constitutional factors in people susceptible to coeliac disease and may detect latent coeliac disease. The sugar absorption test may therefore be helpful in family studies of coeliac disease.

(Gut 1993; 34: 354-357)

The incidence of coeliac disease is not decreasing, but the clinical picture is changing from the classic form in very young children towards the atypical form in school age children and adolescents.' It has been suggested that this delay in the development of symptomatic coeliac disease could be the result of the prolonged period of breast feeding and subsequent delayed introduction of and exposure to gluten. ${ }^{2}$ Maki et $a l^{3}$ described four patients with so called latent coeliac disease, who developed coeliac disease 2 to 9 years after histological examination of the small bowel was normal on a diet containing gluten.

IgA antibodies detected against reticulin and endomysium were shown in $12 \%$ of the family members; accompanied by villous atrophy in $9 \%$ and without villous atrophy in 3\%.' It remains to be seen whether the latter group with a low grade immunological reaction preceding coeliac disease should be considered as another example of latent coeliac disease. This low grade immunological reaction could be the reflection of a preexistent change in the barrier function of the small intestinal mucosa. In some of the patients with latent coeliac disease minor histological changes, such as an increased lymphocyte count, were found before they developed IgA antibodies and coeliac disease. ${ }^{3}$ Two of the four patients with latent coeliac disease were related in the first degree to patients with coeliac disease. In first degree relatives, asymptomatic patients with coeliac disease have been described with a prevalence as high as $10 \% .^{+}$Whether these patients can also be considered to have had latent coeliac disease is unknown. Usually they have not been investigated previously because of a lack of symptoms.

In other immunological gastrointestinal diseases such as food allergy, it has been suggested that disturbances in the functional integrity, responsible for the barrier function of the small bowel mucosa, could play a role in the development of clinical symptoms. In 'full blown' coeliac disease, the histology of the mucosal structure, as well as the functional integrity of the small bowel mucosa, are impaired. ${ }^{\text {" }}$ If latent coeliac disease is a precurser of coeliac disease itself, the functional integrity of the small bowel could already be altered before gross histological abnormalities are found.

Intestinal permeability, as measured by the 


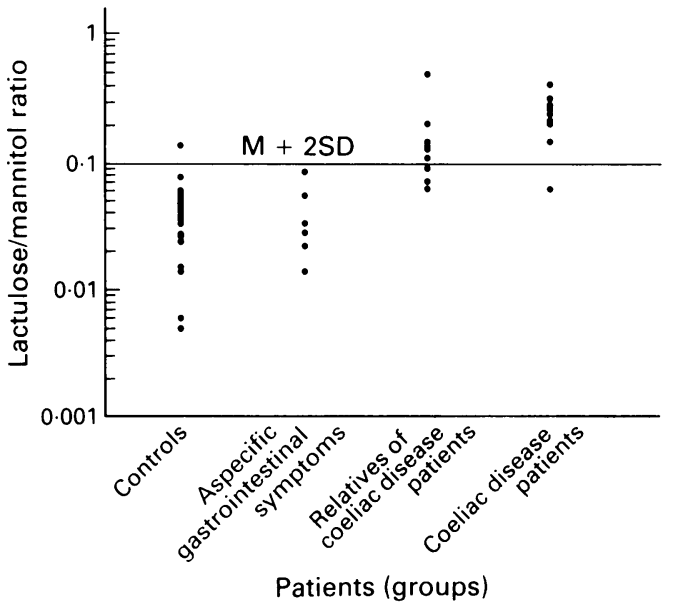

Figure: Individual lactulose/mannitol ratio of 22 healthy controls, nine coeliac disease patients, 10 relatives of coeliac disease patients and six patients with aspecific gastrointestinal symptoms. The horizontal line represents the upper limit of the lactulose/mannitol ratio in healthy controls (mean $+2 S D)$.

sugar absorption test, is considered to reflect functional integrity. It is suggested that the passive absorption of molecules $0.5 \mathrm{~nm}$ - for example lactulose - is increased by oedema, mucosal inflammation, and villous atrophy whereas the absorption of molecules $<0.5 \mathrm{~nm}-$ for example mannitol - is unchanged or impaired. The urinary lactulose/mannitol ratio is said to provide a sensitive non-invasive index of the functional integrity of the small bowel mucosa. $^{78}$

This study aimed to determine if intestinal permeability, as assessed by the sugar absorption test, is different in relatives of coeliac disease patients compared with coeliac disease patients, healthy controls, and patients not related to coeliac disease patients, with aspecific gastrointestinal symptoms in which coeliac disease was excluded by intestinal biopsy investigation.

\section{Patients}

The group characteristics are summarised in Table I. Nine patients with moderate to severe villous atrophy shown by intestinal biopsy specimen were classified as having coeliac disease. These patients were either newly diagnosed or in partial remission and were not adhering to a gluten free diet. Ten patients were first degree relatives of (biopsy proved) coeliac disease patients, of whom seven had aspecific gastrointestinal symptoms such as malaise, abdominal cramps, or abnormal stools, while three had no symptoms at all. Five of 10 relatives of coeliac disease patients had no histological abnormalities on intestinal biopsy specimen. The other five patients had no villous atrophy but had a slightly increased intraepithelial lymphocyte count on intestinal biopsy specimen. The latter group would be classified as Marsh 1 on the criteria recently suggested by Marsh et al." Six patients, not related to coeliac disease patients, had aspecific gastrointestinal symptoms, but no villous atrophy on intestinal biopsy specimen. Twenty two normal adults without any gastrointestinal symptoms and without relatives with coeliac disease served as controls. For ethical reasons intestinal biopsies were not performed in healthy controls.

\section{Methods}

After an overnight fast the patient emptied his or her bladder and drank a solution containing $2 \mathrm{~g}$ mannitol, $5 \mathrm{~g}$ lactulose and $40 \mathrm{~g}$ sucrose, made up to $100 \mathrm{ml}$ with demineralised water, to give an osmolality of approximately $1650 \mathrm{mosm} / \mathrm{l}$. For the first 2 hours after drinking the test fluid, no food or fluid was allowed and all the urine passed in the 5 hours after they had drunk the test fluid was collected. Chlorohexidine digluconate $20 \%$ $(0.5 \mathrm{ml})$ was added to the urine as a preservative. The urine volume was measured and aliquots were stored frozen at $20^{\circ} \mathrm{C}$. To calculate the lactulose/mannitol ratio samples were analysed for lactulose and mannitol by gas chromatography as previously described."

STATISTICAL ANALYSIS

The non-parametric Mann-Whitney $U$ test was used for statistical analysis of the data. A p value $<0.05$ was considered statistically significant.

\section{Results}

The mean lactulose/mannitol ratio in urine from the four groups is summarised in Table II. The lactulose/mannitol ratio in coeliac disease patients is significantly higher than in both the healthy controls $(p<0.0001)$ and in patients with aspecific gastrointestinal symptoms $(\mathrm{p}=0.002)$. The lactulose/mannitol ratio in relatives of coeliac disease patients is significantly lower than in coeliac disease patients $(p=0 \cdot 04)$ but significantly higher than that in either healthy controls $(\mathrm{p}<0.0001)$ and patients with aspecific gastrointestinal symptoms $(p=0 \cdot 002)$. The lactulose/ mannitol ratio is not significantly different in healthy controls and patients with aspecific gastrointestinal symptoms $(p=0 \cdot 74)$.

The mean levels of mannitol excretion in urine in the four groups are summarised in Table II. The differences between the groups are not significant. The mean levels of urinary lactulose excretion in the four groups are summarised in Table II. The differences between the groups are generally similar to the differences in the lactulose/mannitol ratio. The differences between coeliac disease patients and relatives of coeliac disease patients, however, can only be seen in the lactulose/mannitol ratio $(p=0.04)$ and not in the urinary lactulose excretion alone $(\mathrm{p}=0 \cdot 17)$.

An lactulose/mannitol ratio 0.099 (mean $(+2 \mathrm{SD}))$ is considered abnormal. On this basis, in eight of nine coeliac disease patients, seven of 10 relatives of coeliac disease patients, none of six patients with aspecific gastrointestinal symptoms, and one of 22 healthy controls were found to have abnormal lactulose/mannitol ratio (Figure).

\section{Discussion}

In 1974 Menzies et al described the theoretical advantages, over other tests, like the xylose test 
of the simultaneous administration of different inert sugars (lactulose/mannitol) and measuring their excretion ratio in urine. Since then many studies have been performed in a variety of gastrointestinal diseases as reviewed by Lifeshitz." Several sugars have been used, such as mannitol, L-rhamnose, lactulose, and cellobiose. As shown by Juby et $a l^{512}$ the lactulose/mannitol test can be considered as a suitable screening test for coeliac disease. In our study we used a slightly modified lactulose/ mannitol test. We substituted glucose, which is absorbed very quickly by the human intestine and therefore probably contributes little to the intestinal osmolarity of the solution, for sucrose as an osmotic filler. It has been shown that the use of a hyperosmolar solution will result in a better discrimination between normal and abnormal conditions of the small bowel. ${ }^{7}$ Both lactulose and mannitol were measured by gaschromatography as previously described. ${ }^{10}$

In this study the sugar absorption test was performed to determine whether relatives of coeliac disease patients, who are known to be at risk of developing coeliac disease, have functional changes comparable with coeliac disease patients. We showed that the lactulose/ mannitol ratio in these relatives is significantly higher than in both healthy controls and patients with aspecific gastrointestinal symptoms. The relatives' lactulose/mannitol ratio is, however, still significantly lower than that in coeliac disease patients. The latter two groups cannot be differentiated by lactulose excretion alone. The increase in lactulose excretion in coeliac disease may reflect epithelial injury, cell shedding, or changes in the intercelluar tight junctions. ${ }^{12}$ Mannitol, which is quite similar in size to xylose, could not differentiate between any group. This confirms the higher sensitivity of the lactulose/ mannitol ratio than the use of one marker, like lactulose. In a recent study, we compared the sugar absorption test with the xylose test in detecting impaired mucosal function and found that the sensitivity of the sugar absorption test is much better than that of the xylose test, whereas the specificity was equal. ${ }^{13}$

Untreated coeliac disease patients have an increased risk of intestinal malignancies. ${ }^{1+}$ For that reason, it seems reasonable to screen first degree relatives whose risk of developing asymptomatic coeliac disease is as high as $10 \%$. None of the 10 relatives showed signs of villous atrophy on histological examination of the small bowel but seven of 10 had increased intestinal permeability. Of these seven, two were asymptomatic while, three showed increased intraepithelial lymphocytes. Therefore, in our study no clear correlation seems to exist between increased intestinal permeability, histological abnormalities of the small bowel, or the occurrence of aspecific gastrointestinal symptoms.

Increased intestinal permeability could facilitate the interaction of gluten with the human immune system thus leading to the production of IgA antibodies and (after prolonged exposure to gluten) to histological damage of the mucosa. It seems unlikely, however, that increased intestinal permeability is a primary factor in the development of coeliac disease. In two recent studies, coeliac disease patients on a gluten free diet had normal intestinal permeability but did react to gluten challenge with an increase in intestinal permeability. ${ }^{15} 16$

There are two possible explanations for the finding that intestinal permeability was increased in seven of 10 relatives of coeliac disease patients who had no histological evidence of the disease. Firstly, this could be a secondary phenomenon of a low grade immunological reaction to gluten that is insufficient to cause histological damage of the small bowel. Secondly, it could reflect latent coeliac disease in which the 'full blown' histological changes will develop in the future, after long term exposure to gluten or to as yet another unknown trigger. Controversy exists over the value of $\operatorname{IgA}$ antigliadin antibodies ( $\operatorname{IgA} \mathrm{AGA})$ in detecting coeliac disease. ${ }^{17}$ Arnason recently presented data that suggest a possible role for IgA AGA in detecting coeliac disease. ${ }^{18}$ In our study, IgA AGA were determined by the Central Laboratorium of the Netherlands Red Cross Blood Transfusion Service (Dr Stapel). In three of six coeliac disease patients positive titres of IgA AGA were found, whereas one of nine relatives had a positive IgA AGA titre. None of the four patients with gastrointestinal symptoms we tested had a positive IgA AGA titre.

We conclude that the sugar absorption test is a sensitive non-invasive test that differentiates between coeliac disease patients and both healthy controls and patients with aspecific gastrointestinal symptoms. Relatives of coeliac disease patients tend to have increased permeability compared with both healthy controls and patients with aspecific gastrointestinal symptoms.

The exact implications of increased intestinal permeability for the development of and screening for coeliac disease remains to be seen. As the time interval between latent and active coeliac disease could be as long as 10 years,${ }^{3}$ the follow up of the patients in this study will help us understand whether increased intestinal permeability (as measured with the sugar absorption test) is a predictor of future coeliac disease, and therefore identify patients with so called latent coeliac disease.

We thank Professor Dr G N J Tytgat for his helpful suggestions in the preparation of the manuscript.

1 Maki M, Holm K. Incidence and prevalence of coeliac disease in Tampere. Coeliac disease is not disappearing. Acta Paediatr Scand 1990; 79: 980-2.

2 Ceccarelli M, Caiulo VA, Ughi C. Is childhood coeliac disease underdiagnosed? [letter]. Eur f Pediatr 1991; 150: 821-2.

3 Maki M, Holm K, Koskimies S, Hallstrom O, Visakorpi JK Normal small bowel biopsy followed by coeliac disease. Arch Dis Child 1990; 65: 1137-41.

4 Auricchio S, Mazzacca G, Tosi R, Visakorpi J, Maki M, Polanco I. Coeliac disease as a familial condition: identification of asymptomatic coeliac patients within family groups. tion of asymptomatic coeliac patients within
Gastroenterology International 1988; 1: 25-31.

5 Juby LD, Rothwell J, Axon ATR. Lactulose/mannitol test: an ideal screen for celiac disease. Gastroenterology 1989; 96: ideal scree.

6 Ukabam SO, Cooper BT. Small intestinal permeability as an indicator of jejunal mucosal recovery in patients with celiac sprue on a gluten-free diet. F Clin Gastroenterol 1985; 7 $232-6$

7 Menzies IS. Absorption of intact oligosaccharides in health and disease. Biochem Soc Trans 1974; 2: 1042-7.

8 Menzies IS. Transmucosal passage of inert molecules in health and disease. In: Skadhauge E, Heintze K, eds. Intestinal absorption and secretion. London: MTP Press, 1983: 527-43. 
9 Marsh MN. Gluten, major histocompatibility complex, and the small intestine. A molecular and immunobiologic approach to the spectrum of gluten sensitivity ("Celiac sprue'). Gastroenterology 1992; 102: 330-54.

10 Jansen G, Muskiet FAJ, Schierbeek H, Berger R, Van der Slik W. Capilary gas chromatographic profyling of urinary, plasma derivates, preceded by a simple and rapid prepurification method. Clin Chim Acta 1986; 157: 277-94.

11 Lifshitz C, Shulman RJ. Intestinal permeability tests: are they clinically useful? f Pediatr Gastroenterol Nutr 1990; 10: 283-7.

12 Juby LD, Rothwell J, Axon ATR. Cellobiose/mannitol sugar test a sensitive tubeless test for coeliac disease: results in test a sensitive tubeless test for coeliac disease:

13 Uil JJ, Van Elburg RM, De Vries RA, Mulder CJJ, Heymans HSA. Changes in mucosal function as determined by the D-xylose test and sugar absorption test in celiac disease. Gastroenterology 1992; 102: A249.
14 Holmes GKT, Prior P, Lane MR, Pope D, Allan RN Malignancy in coeliac disease-effect of a gluten free diet. $G u$ 1989; 30: 333-8.

15 Howden CW, Robertson C, Duncan A, Morris AJ, Russell RI Comparison of different measurements of intestinal permeability in inflammatory bowel disease. Am $\mathcal{F}$ Gastroenterol 1991; 86: 1445-9.

16 Stenhammar L, Falth-Magnusson K, Jansson G, Magnusson $\mathrm{KE}$, Sundqvist $\mathrm{T}$. Intestinal permeability to inert sugars and different-sized polyethyleneglycols in children with celiac disease. F Pediatr Gastroenterol Nutr 1989; 9: 281-9.

17 Lerner A, Lebenthal E. The controversy of the use of antigluten antibody (AGA) as a diagnostic tool in celiac disease (editorial). I Pediatr Gastroenterol Nutr 1991; 12: 407-9.

18 Arnason JA, Gudjonsson H, Freysdottir J, Jonsdottir I Valdimarsson $\mathrm{H}$. Do adults with high gliadin antibody concentrations have subclinical glutenintolerance? $G u$ 1992; 33: 194-7. 